\title{
Factors affecting the outcome in multiple gestations
}

\author{
Venugopal $\mathbf{S}^{1}$, Patil $\mathbf{R B}^{2}$ \\ ${ }^{1}$ Dr Venugopal S, Assistant Professor, ${ }^{2}$ Dr R.B. Patil, Professor. Both are affiliated with Department of Pediatrics, \\ Shimoga Institute of Medical Sciences Shimoga, Karnataka, India
}

Address for Correspondence: Dr. Venugopal.S, Email: drvenugopalped@gmail.com, \# no. 204 Mac Gann hospital staff quarters, Shivamogga Institute of Medical Sciences, Shivamogga, Karnataka, India

\begin{abstract}
Introduction: Twin births are the commonest form of multiple births. Twins have attracted considerable attention and excited curiosity from early times as a biological variety in the study of the human species. Twin pregnancy is considered as high risk pregnancy. There is poor neonatal outcome in terms of mortality and morbidity. Materials and methods: A retrospective study was conducted from Jan 2015 to Jan 2014 Mac Gann Government General hospital. During this period there were 2643 deliveries occurred out of which 48 twins and 8 were triplets. Results: In the present study, Incidence of twin pregnancy is $18 / 1000$ live birth. Monozygotic twinning rate is $4.2 / 1000$ live births, while dizygotic twinning rate is $14.2 / 1000$ live births. Perinatal mortality in twins is $177 / 1000$ births as compared to $74.3 / 1000$ births in singleton pregnancy i.e., 2.38 times that of singleton pregnancy. In twin pregnancy Perinatal mortality rate in $1^{\text {st }}$ twin is $62.5 / 1000$ live births while in second twin it is $114.5 / 1000$ births. Frequency of IUGR in twin pregnancy is $85.4 \%$. Risk of preterm labour in twin pregnancy is $64.5 \%$. IUGR babies are more in monochorionic than in dichorionic placenta. Conclusion: Perinatal mortality in twin is higher than in of singleton pregnancy. Risk of single fetal loss (antepartum deaths) in twin pregnancy is higher than risk of both fetal losses. Perinatal mortality rate in $2^{\text {st }}$ twin is double compared to first twin. Perinatal mortality increases as the gestational age decreases. Frequency of IUGR in twin pregnancy is very high and more in monochorionic than in dichorionic placenta
\end{abstract}

Key words: Monochorionic, Dichorionic, Monozygotic, Dizygotic, Perinatal.

\section{Introduction}

Twin births are the commonest form of multiple births. Twins have attracted considerable attention and excited curiosity from early times as a biological variety in the study of the human species. The knowledge regarding the genetic and biological structure of twins is being used with great advantage in medical research, especially in modern surgery. In organ transplantation, which is becoming more and more successful day by day, the co-twin is the best possible donor. The monozygotic twin is a real boon for the surgeon working on kidney transplant [1]. Twins are more frequent after the second pregnancy and with advancing maternal age [2]. There is high rate of dizygous twinning has been described for women who has conceived within one month after stopping use of oral contraceptives[3]. Large numbers of births are encountered in lower socio-economic classes as compared to upper socio economic classes [4].

Manuscript received: $23^{\text {rd }}$ Oct 2015

Reviewed:29 $9^{\text {th }}$ Oct 2015

Author Corrected: $19^{\text {th }}$ Nov 2015

Accepted for Publication: $28^{\text {th }}$ Nov 2015
Twin pregnancy is considered as high risk pregnancy. There is poor neonatal outcome in terms of mortality and morbidity [5]. Factors influencing poor neonatal outcome includes maternal, fetal and placental factors. Anticipation of such factors can improve neonatal outcome in twin pregnancy. There are few studies on neonatal outcome in twin pregnancy in Indian literature and hence this study has its own real importance.

\section{Aim of the study}

1. To find out the incidence of twin pregnancy in our hospital.

2. To find out the perinatal mortality rate and morbidity rate in twin pregnancy.

3. To study factors (maternal/ fetal/ placental) influencing neonatal outcome in twin pregnancy

\section{Materials and Methods}

A retrospective study was conducted from Jan 2015 to Jan 2014 Mac Gann Government general hospital. 
During this period there were 2643 deliveries of which 48 twin pregnancy and 8 were triplets. The study was approved by the ethical committee of our hospital. Details of obstetric history were noted from case sheet. Obstetric complications were looked and noted. Details of twin babies after birth with regard to maturity date of birth, time of birth, birth weight, presentation, mode of delivery, indications for NICU admissions were recorded from case sheet. Birth weight discordance and inter-twin time interval were recorded. An examination detail of the placenta which was done to determine the types of placenta was collected from case sheet. Zygosity is also determined on the basis of USG records from case sheet. NICU admitted babies, records of neonatal complications, course in NICU, risk factors, investigations done, records were collected from NICU case sheets

Inclusion Criteria - Live and still born babies (both twins) with gestational age more than or equal to 28 weeks or if gestational age was not known then weight more than 1000 gms were included in the study, early neonatal deaths and morbidity were included this study.

Exclusion Criteria - babies born outside this hospital and dying in the hospital NICU were excluded from the study.

Statistical Analysis- Paired t test was used to see the statistical significance

\section{Results}

During this period there were 2643 deliveries occurred out of which 48 were twin pregnancy and 5 were triplets.

Table 1: Frequency of mozygous and dizygous twin pairs

\begin{tabular}{|c|c|c|}
\hline Zygosity & Total no. of birth & Frequency/ 1000 live birth \\
\hline Monozygous & 11 & $4.2 / 1000$ \\
\hline Dizygous & 37 & $14.2 / 1000$ \\
\hline Total & $\mathbf{4 8}$ & \\
\hline
\end{tabular}

From the above table it is clear that frequency of monozygotic twins is 4.2/1000 live birth and dizygous is $14.2 / 1000$ live births

Table 2: Percentage of antepartum single and both fetal losses in twin pregnancy

\begin{tabular}{|c|c|c|}
\hline Antepartum fetal loss & Total no. of twins pair & Percentage \\
\hline Single fetal loss & 9 & 18.7 \\
\hline Both fetal loss & 1 & 2 \\
\hline
\end{tabular}

Above table shows single fetal loss in twin pregnancy is $18.7 \%$ where both fetal loss is $2 \%$.

Table 3: Comparison between still birth rate, early neonatal death rate and perinatal mortality rate of first and second twin

\begin{tabular}{|l|c|c|c|c|}
\hline & First twin & $\begin{array}{c}\text { Rate per 1000 live birth/ } \\
\text { live birth }\end{array}$ & $\begin{array}{c}\text { Second } \\
\text { twin }\end{array}$ & $\begin{array}{c}\text { Rate per 1000 live birth/ live } \\
\text { birth }\end{array}$ \\
\hline Still birth & 5 & 52.0 & 6 & 62.5 \\
\hline Early neonatal death & 1 & 10.4 & 5 & 52.0 \\
\hline Perinatal death & 6 & 62.5 & 11 & 114.5 \\
\hline
\end{tabular}

From the above table still birth rate, early neonatal death rate and perinatal death rate is more in second twin than first twin. Average birth weight in twin pregnancies is $1.81 \mathrm{~kg}$. 
Table 4: Distribution of twin pair and perinatal death according to gestational age

\begin{tabular}{|c|c|c|c|}
\hline Gestational age in week & No. of twins pair & Total Perinatal death & $\begin{array}{c}\text { Percentage of Perinatal } \\
\text { death }\end{array}$ \\
\hline 28 & 1 & 1 & 100 \\
\hline 30 & 8 & 5 & 31 \\
\hline 32 & 3 & ---- & 22.7 \\
\hline 34 & 11 & 5 & 18.1 \\
\hline 36 & 11 & 4 & 7.1 \\
\hline 38 & 14 & 2 & \\
\hline Total & $\mathbf{4 8}$ & & \\
\hline
\end{tabular}

From the above table perinatal death increases as the gestational age decreases

Table 5: Distribution of twin babies, Preterm births, IUGR babies, weight discordance and Perinatal death according to Zygosity

\begin{tabular}{|l|c|c|}
\hline Zygosity & Monozygous & Dizygous \\
\hline Total pair & $11(22.9 \%)$ & $37(77.0 \%)$ \\
\hline Preterm labour (no. of twin pregnancy) & $6(54 \%)$ & $25(67 \%)$ \\
\hline Total no. of IUGR babies & $20(90.9 \%)$ & $62(83.7 \%)$ \\
\hline Total no. of pair with weight discordance $>25 \%$ & $6(54.5 \%)$ & $8(10.8 \%)$ \\
\hline Perinatal death & $50 \%$ & $9 \%$ \\
\hline
\end{tabular}

Table 6: Distribution of LBW Babies in twin and Singleton Pregnancy

\begin{tabular}{|c|c|c|c|}
\hline Type of pregnancy & Total no. of babies & No of babies weight $<\mathbf{2 . 5} \mathbf{~ k g}$ & Percentage \\
\hline Twin & 96 & 82 & 85.4 \\
\hline Singleton & 2595 & 779 & 30 \\
\hline
\end{tabular}

$\mathrm{P}<0.05$

From the above table it is clear that LBW babies are 3 times more common in twin pregnancy than singleton pregnancy

\section{Discussion}

\section{Frequency of mozygous and dizygous twin pairs}

Talsania et al [1] has reported twin pregnancy incidence in rural communities of Gujarat at 10.10 per 1000 live birth. In contrast, dizygotic twining rates vary greatly among population from 4 -50 per 1000 live births. John P Cloherty (2004) [6], the rate of monozygotic twinning has remained relatively constant $3.5 / 1000$ \& dizygotic twinning is approximately 10/1000 live birth.

Mc Carthy BJ Suchs [7] reported that monozygotic twinning occurs at fairly constant rate of 3.5/1000 live birth . In contrast, dizygotic twinning rates vary greatly amount population from 4-50/1000 live birth. William $21^{\text {st }}$ edition [8] mentioned that frequency of monozygotic twin birth is relatively constant worldwide approximately 1 per 250 births while incidence of dizygotic twinning varies. In the present study incidence of twin pregnancy is 18/1000 live birth, incidence of monozygotic twins is 4.2/1000 live birth and incidence of dizygotic twin is $14.2 / 1000$ live birth.

Percentage of antepartum single and both fetal losses in twin pregnancy.

Benirschke $\mathrm{K}$ and D'Alton $\mathrm{M} \mathrm{E}[5]$ showed that frequency of single demise is $0.5 \%-6.8 \%$. Rydhstrom [9] reported that both fetuses died in $0.5 \%$ in twin pregnancy. Present study shows single fetal loss in twin pregnancy is $18.7 \%$ in which both fetal losses are $2 \%$.

Comparison between still birth rate, early neonatal death rate and Perinatal mortality rate of first and second twin.

John P Cloherty (2004)[6] mentioned that the second twin is at greater risk for perinatal death being more prone for malpresentation (35-40\% of second presenting 
verses $15-20 \%$ of first twin are non vertex), cord compression, asphyxia and perinatal depression.

Nkata M (1999)[10] suggested that Perinatal mortality in twin gestation was high (141/1000) and affected mostly $2^{\text {nd }}$ twin $(72 \%)$.

Sheay W (2004)[11] stated that Perinatal mortality was $37 \%$ higher in second-born twin than first born.

J.R Srivastavan[12] Perinatal mortality is more in second twin.

In the present study first twin - still birth rate is 52/1000 live birth, early neonatal death is $10.4 / 1000$ live birth Perinatal death is 62.5/1000live birth. And in second twin still birth rate is $62.5 / 1000$ live birth, early neonatal death is $52.0 / 1000$ live birth, Perinatal death is 114.5/1000 live birth.

\section{Distribution of twin pair and Perinatal death} according to gestational age

Williams, $17^{\text {th }}$ ed [13] also stated that, preterm birth is major reason for increased risk of neonatal death and morbidity in twins. Newton W Keital D [14] mentioned that average birth weight in twin birth is $2.39 \mathrm{~kg}$

Houlten MCC [15] stated that growth restriction is common in twin pregnancy and rate vary from $25 \%$ $30 \%$

In the present study increased mortality is seen in preterm babies.

Distribution of twin babies, preterm births, IUGR babies, weight discordance and Perinatal death according to zygosity

Talsania et al [1] has reported twin pregnancy incidence in rural communities of Gujarat at 10.10 per 1000 live birth.

Williams [13] stated that degree of IUGR in monozygotic twins is likely to be greater than dizygotic twins. Williams [13] stated that monozygotic twin pair were more discordant in size than dizygotic twin pairs.

In the present study preterm labour is $54 \%$, IUGR is 90.9\%, weight discordance is $54.5 \%$ and Perinatal death is $50 \%$ in monozygous twin and preterm labour is $67 \%$, IUGR $83.7 \%$, weight discordance is $10.8 \%$ and Perinatal death is $9 \%$ in dizygous twin.

Distribution of LBW Babies in twin and Singleton Pregnancy
Szekven H.O [16] mentioned that 55\%were low birth weight babies. Adam C Allen AC[17] perinatal death and significant perinatal mortality occurred in infant weighing $<1500$ gms o $r<32$ weeks of gestation

In the present study LBW of singleton pregnancy is $30 / 1000$ live birth and 85.4/1000 live birth in twin pregnancy.

\section{Conclusion}

Incidence of twin pregnancy is increasing day by day. It is seen more in dizygotic than in monozygotic type due to increased use of ovulation drugs and artificial reproductive technique. Perinatal mortality in twins is almost double than that of singleton pregnancy, due to preterm births, congenital malformation and complications associated with twin pregnancy.

Risk of single fetal loss in twin pregnancy is significantly high when compared to both fetal losses. Perinatal mortality rate in $2^{\text {st }}$ twin is double compared to first twin due to inter twin delivery time which causes asphyxia of the second twin.

Average birth weight in twin pregnancy is $1.81 \mathrm{~kg}$, which is the most common factor for mortality and morbidity in twins. Frequency of IUGR in twin pregnancy is very high.

Perinatal mortality increases as the gestational age decreases, due to complications related to low birth weight. Perinatal mortality is 5 times more in monochorionic diamniotic placenta than in diamniotic dichorionic placenta, as complications like twin to twin transfusion, conjoint twins, intra uterine fetal demise and others are associated more in monochorionic placenta. IUGR babies are more in monochorionic than in dichorionic placenta. Mortality and morbidity rapidly increases as the inter twin delivery time increases and goes beyond $15 \mathrm{~min}$. So it should be ideal to keep intertwin delivery time less than $15 \mathrm{~min}$ and definitely not beyond $30 \mathrm{~min}$.

Abbreviation Used: NICU- Neonatal intensive care unit, IUGR- Intrauterine growth retardation, USG Ultrasonography

Ethical approval: Obtained from Institutional Ethics Committee (Human Studies)

Funding: No funding sources.

Conflict of Interest: The authors declare no conflict of interest. 


\section{Bibliography}

1. Talsania NJ, Purohit CK. A study of twin births in rural communities of Gujarat. Indian Pediatr. 1990 Mar;27(3):276-9.

2. Gedda L Twin in the history and science. Springfield, Illinois Charles C Thomas 1961, pp52-99.

3. Rothman KJ. Fetal loss, twinning and birth weight after oral-contraceptive use. N Engl J Med. 1977 Sep 1;297(9):468-71.

4. Ghosh S, Ramanujacharyulu TK. Study of twin births in an urban community of Delhi. Indian $\mathrm{J}$ Med Res. 1979 Jul;70:70-7.

5. Benirschke K., Kim CK. Multiple Pregnancies. N. Engl. J. Med. 1973; 288: 1276-1329.

6. John cloherty et al Manual of neonatal care $5^{\text {th }}$ edition 2004

7. Mc Carthy BJ Suchss BP et al the epidemiology of neonatal death in twins Am J Obstet Gyneco 1965;91:400-407.

8. Williams , Obst $21^{\text {st }}$ edition multiple pregnancy 767 767.

9. Rydhstroem H. Pregnancy with stillbirth of both twins. Br J Obstet Gynaecol. 1996 Jan;103(1):25-32.
10. Nkata M. Perinatal mortality in twin deliveries in a general hospital in Zambia. J Trop Pediatr. 1999 Dec;45(6):365-7.

11. Sheay W, Ananth CV, Kinzler WL. Perinatal mortality in first- and second-born twins in the United States. Obstet Gynecol. 2004 Jan;103(1):63-70.

12. Bhalla JN, Bhalla M, Srivastava JR. A study of some maternal factors associated with twinning. Indian Pediatr. 1977 Jul;14(7):539-43.

13. Williams. Multiple pregnancy. Obstetrics $17^{\text {th }}$ Edition, 503-515.

14. Newton W, Keith L, Keith D. The Northwestern University multihospital twin study. IV. Duration of gestation according to fetal sex. Am J Obstet Gynecol. 1984 Jul 15;149(6):655-8.

15. Houlton MC, Marivate M, Philpott RH. The prediction of fetal growth retardation in twin pregnancy. Br J Obstet Gynaecol. 1981 Mar;88(3):264-73.

16. Ho SK, Wu PY. Perinatal factors and neonatal morbidity in twin pregnancy. Am J Obstet Gynecol. 1975 Aug 15;122(8):979-87.

17. Adam C, Allen AC, Baskett TF. Twin delivery: influence of the presentation and method of delivery on the second twin. Am J Obstet Gynecol. 1991 Jul;165(1):23-7.

\section{How to cite this article?}

Venugopal S, Patil RB. Factors affecting the outcome in multiple gestations. Pediatr Rev: Int J Pediatr Res 2015; 2(4):72-76.doi:10.17511/ijpr.2015.i04.07 